\title{
Forecasting Grain Production and Static Capacity of Warehouses Using the Natural Neighbor and Multiquadric Equations
}

Elizabeth Giron Cima ${ }^{1}$, Weimar Freire da Rocha-Junior ${ }^{1}$, Gustavo Henrique Dalposso², Miguel Angel Uribe-Opazo ${ }^{1}$, Willyan Ronaldo Becker ${ }^{1}$

${ }^{1}$ Western Paraná State University (UNIOESTE), Cascavel-PR, Brazil

${ }^{2}$ Federal University of Technology - Paraná (UTFPR), Toledo-PR, Brazil

\begin{abstract}
The strategic logistics of agricultural production and storage aggregates information related to production and storage. In this sense, time, location, and distance from producer and consumer markets are considered, emphasizing the importance of grain storage and production logistics. The Natural Neighbor and multiquadric equation are spatial interpolation methods used to predict these variables value at non-sampled locations, for asymmetric and categorical data, respectively. This study investigated the spatial prediction of grain production (tons) (soybean, first crop corn, second-crop corn, and wheat) in the 2016/2017 growing season and qualitative data on the static capacity of warehouses in the 2017/2018 growing season. The result obtained through the spatial interpolation using the natural neighbor method was coherent, as it showed the high variability of grain production relative to the different meso-regions. Therefore, the method was appropriate because it allowed predicting the behavior of grain production in the 2016/2017 growing season in the state of Paraná-Brazil, making it possible to identify regions of higher or lower production. The result of the spatial interpolation using the multiquadric equations allowed identifying a higher predominance of storage units with a low static capacity of warehouses, but also enabled the detection of regions with a static capacity of warehouses that varied from the medium to the high category in the state of Paraná, Brazil.
\end{abstract}

\section{Keywords}

Agricultural, Digital agriculture, Geographic location, Radial basis function, Spatial interpolation.

Cima, E. G., da Rocha-Junior, W. F., Dalposso, G. H., Uribe-Opazo, M. A. and Becker, W. R. (2021) "Forecasting Grain Production and Static Capacity of Warehouses Using the Natural Neighbor and Multiquadric Equations", AGRIS on-line Papers in Economics and Informatics, Vol. 13, No. 3, pp. 3-14. ISSN 1804-1930. DOI 10.7160/aol.2021.130301.

\section{Introduction}

Brazil stands out as one of the largest food producers in the world, especially in the production of soybean and corn (Cicolin and Oliveira, 2016; Paludo et al., 2020). The state of Paraná is the second-largest Brazilian soybean and corn producer, with a soybean yield of 21.6 million tons (17\% of the national yield) and 15 million tons of corn ( $15 \%$ of the national yield) in 2018 (Conab, 2020). Despite the great advances of Brazilian agribusiness in terms of production, the country faces a storage deficit, which limits the efficiency of the system as a whole, increasing the final cost of production (Cima et al., 2020). In the coming years, Brazil will probably have a high storage deficit of its agricultural production (Baroni et al., 2017).

Zdráhal et al. (2021) inform in their in their studies on economic development that Brazil is considered a major exporter of soybean and also has an expressive participation in the production chain of poultry and beef, it also collaborates with the global food supply, within the economic and environmental sustainability vision.

Given the expressive and strategic role that grain production and agricultural storage has in agribusiness in the state of Paraná, the approach the sufficiency of static capacity in warehouses uses indicators of grain supply associated with the demands for storage capacity (Fliehr et al., 2019).

The literature shows that study of geostatistics is a technique that promotes the analysis and prediction of continuous variables that are spread over space and time and that considers the spatial correlation between the sample points 
at which they are used to map spatial variability (Narany et al., 2014; Bachir et al., 2016; Song et al., 2019).

Accuracy in estimating the spatial distribution of grain production and the static capacity of warehouses requires efficient mechanisms and compatibility of methods and computational resources (Righi and Basso, 2016). Usually, interpolation methods are used to generate distributed surfaces of a given variable from point data. They contribute to the spatial understanding of attributes without the need to collect data in the entire area of interest (Righi and Basso, 2016).

Spatial interpolation methods have been widely used in several areas of knowledge such as Agrarian Sciences with the trend of digital agriculture (agriculture 4.0) and artificial intelligence (Chen and Cai, 2019). The Natural Neighbor interpolation method is expressively used to work with dispersed (asymmetric) data, whereas multiquadric equations are used to interpolate qualitative variables (Tsidaev, 2016; Yamamoto et al., 2018).

Recent studies have shown the wide application and advantages of spatial interpolation methods using the Natural Neighbor (NN) interpolator and multiquadric equations (Belinha et al., 2017; $\mathrm{Ku}$ et al., 2020). The spatial interpolation methods $\mathrm{NN}$ and the radial basis function, also known as the study of multiquadric equations, allow the knowledge of the spatial behavior of variables at non-sampled locations, facilitating the decisionmaking (Sampedro et al., 2019; Millan et al., 2020). The multiquadric equations it allows interpolating qualitative variables, which often appears in studies related to precision agriculture (Saeedpanah et al., 2020).

The study of strategies for production and storage contributes to greater prudence and scientific understanding of the challenge that involves the grain production and its relationship the storage system local and regional (SteinerNeto et al., 2017). Currently, studies have focused on the mapping and interpolation of agricultural data aiming at verifying the spatial variability of soybean yield that is closest to the reality of the planted crop (Dalposso et al., 2019). There is a lack of collective consensus in the literature regarding the choice of the best interpolator, which may be related to extrinsic factors such as the chosen spatial resolution (geographic scale), sample size, and data integrity (Aanjos et al., 2017).
In this sense, the interpolation of spatial data using the NN interpolator is an extremely important computational technique in science and engineering (Sekulić et al., 2020). It is a fundamental tool, being favored by the spatial autocorrelation associated with its covariates (Sekulić et al., 2020).

Sampedro et al. (2019) stated that studies related to the NN interpolation method should pave the way for new studies nowadays. Li, Chen and Luo (2016) and Martyshko, Ladovskiy and Byzov (2016) observed that the NN interpolation method has an effective potential for solving problems in nonlinear data, in addition to being efficient enough to be used in the interpolation of spatial data.

According to Seydaoğlu (2019), the analysis of spatial interpolation using multiquadric equations allows verifications of the variables in studies and higher understanding of this information. Gao et al., (2020), reported that the methods of spatial interpolation through multiquadric equations are widely studied and used in studies, with promising results. In this context, considering the production cycle of soybean, corn, and wheat and the effective demand for static capacity of warehouses, it is necessary to understand the behavior of the spatial variability of these variables, allowing a strategic view of the agents regarding production and storage of the regions.

Yamamoto and Landim (2013) observed the need for a binary coding for regionalized variables with discrete characteristics, and each type that make up the discrete variable is interpolated using multiquadric equations without using indicator kriging due to the need for a variogram for the discrete variable.

Recent studies have shown the effectiveness of the spatial interpolation of discrete variables using multiquadric equations (Zhang et al., 2014; $\mathrm{Li}$ and Chen, 2016; Patel and Rastogi, 2017; Yamamoto et al., 2018; Musashi, 2018; Seydaoglu, 2019; Santos and Yamamoto, 2019; Millan et al., 2020). Nourani et al., (2018) emphasized the importance of using the radial basis function, indicating that the efficiency of the method is due to lower uncertainties involved in the obtained data, improved methods that do not use the regular grid, but a radial base function, have become a reference for many studies (Briani et al., 2017; Golbabai and Mohebianfar, 2017; Soleymani and Ullah, 2018; Moradi et al., 2020). 
This study aims to show the use of the NN spatial interpolation method in the analysis of grain production, as they are a possible alternative mentioned in the literature.

Another justification of the present study is to show the efficiency of using the interpolation method using multiquadric equations in a qualitative database of the static capacity of warehouses and present its efficiency in the presentation of estimated data at a non-sampled location.

Thus, this study aimed to evaluate the use of the NN interpolation to understand the behavior of the spatial variability of grain production (soybean, first crop corn, and second crop corn, and wheat) in the state of Paraná, Brazil. Also, the present study tried to check the efficiency of the multiquadric equations in a qualitative database of the static capacity of warehouses and present its efficiency in estimate data at a nonsampled location.

The conceptualization and formulation of this study were obtained from the need to understand the spatial behavior of grain production and the static capacity of warehouses in municipalities and meso-regions, as grain production is growing and constant. In contrast, there is an attenuating mismatch and present in grain storage systems in the state of Paraná, Brazil.

\section{Material and methods}

The study area comprises the 399 municipalities in the state of Paraná, Brazil, distributed across its ten meso-regions (Figure 1). Georeferenced data on grain production (soybean, first crop corn, second crop corn, and wheat) and static storage capacity in tons were obtained from the National Supply Company (Conab, 2019). This study shows an application of the spatial interpolations Natural Neighbor (NN) from an original database of grain production (tons) in the 2016/2017 growing season (Seab, 2020) and application of the multiquadric equations an database of static capacity of warehouses in the 2017/2018 growing season (Conab, 2019). Exploratory analysis of data on grain production and static capacities of warehouses was performed using descriptive statistics to understand the behavior of these variables under study.

The analysis of the frequency distribution, histogram, and boxplot was performed to verify the behavior of these variables relative to the trend of data concentration (symmetric or asymmetric trend). The variance of the data was also analyzed to verify the dispersion of the data associated with its distance. The coefficient of variation was analyzed according to Cima et al., (2020 b). A coefficient of variation higher than or equal to $30 \%$ $(\mathrm{CV} \geq 30 \%)$ means that the data have high dispersion. For symmetric data exists spatial models, based on geometric criteria in which
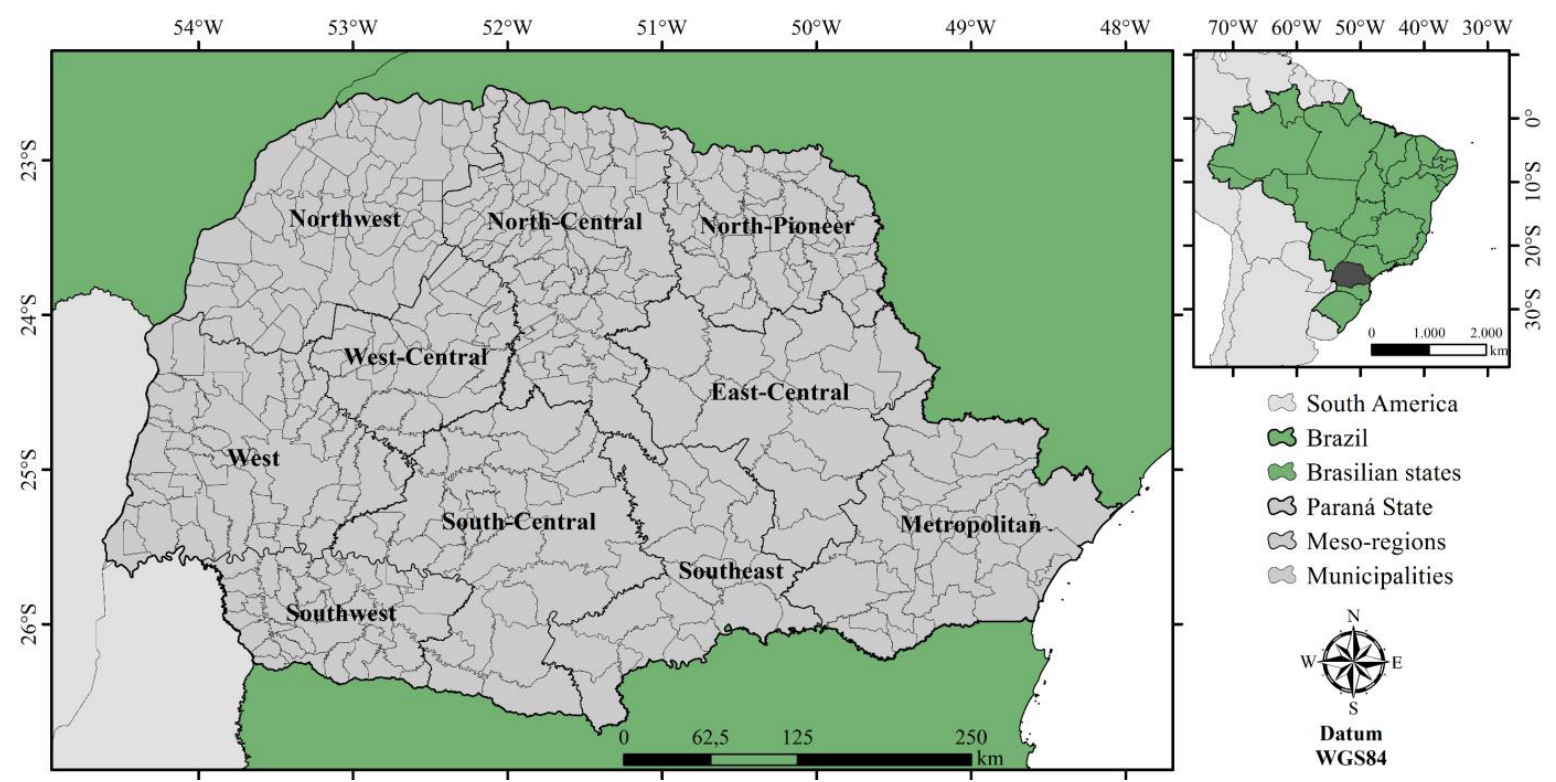

Source: Adapted from Seab-Deral (2020)

Figure 1: Delimitation of the study área. 
Euclidean distances are considered. Geostatistics in its classic form could not be used, considering the data's asymmetry under analysis (UribeOpazo et al., 2012; Tsidaev, 2016). In this study, the variable grain production (tons) is asymmetric.

Sibson (1981) present for asymmetric data, the Natural Neighbor (NN) interpolation method is based on the Voronoi (1908) polygon network of the set of dispersion points. Interpolation using the NN method creates weights for each entry point based on their considered area of influence (Tsidaev, 2016). The interpolation occurs considering the nearest neighbor interpolator $(\mathrm{NN})$, shown in Equation (1).

$$
Z(x, y)=\sum_{i=1}^{n} w_{i} Z_{i}
$$

on what,

$Z$ is the interpolated value for the regular grid node $(\mathrm{x}, \mathrm{y})$, and $w_{i}$ represents the weights at $Z_{i}$ of the sample that is next to the subset. For the spatial study of categorical variables the spatial interpolation using multiquadric equations is recommended (Yamamoto and Landin, 2013). This methods have similarity with kriging interpolation used in methodology geostatistics, which uses an omnidirectional variogram for presenting isotropic behavior of the data. Multiquadric equations provide information on non-sampled points as a function of sampled points. In this study, the variable static capacity of warehouses is not numerical but qualitative, being represented by different $\mathrm{K}=3$ levels (low, average and high), which measures the degree of spatial correlation at each specific location. Following is the description of the steps that corresponded to the implementation of multiquadric equations, according to Yamamoto and Landim (2013). The indicator functions are given by Equations (2) to (7).

$$
Z^{*}\left(X_{0}\right)=\sum_{i=1}^{n} C_{i} \phi\left(x_{i}-x_{0}\right)+a_{0},
$$

on what,

$C_{i}, i=1, N$ : are the coefficients of the multiquadric equation;

$a_{0}$ : and a constant term that improves the accuracy of the radial basis function (Yamamoto, 2002);

$\left(x_{i}-x_{0}\right)$ : is the distance between the $\mathrm{i}$-th sampling point and the point to be interpolated, following the geostatistical notation, and $\phi$ is the radial basis function.

According to this information, the multiquadric equation can be used as a local interpolation method, through with neighboring points closest to the point to be interpolated $(n)$. Yamamoto and Landim (2013) demonstrated that Equation (2) can be written in dual form considering all the imposed conditions of restriction, according to Equation (3).

$$
Z^{*}\left(X_{0}\right)=\sum_{i=1}^{n} W_{i} Z\left(x_{i}\right)
$$

in which this equation has the constraint condition $\sum_{i=1}^{n} W_{i}=1$, that is, a condition equal to that used in ordinary kriging, according to the description below.

The weights of Equation (3) are obtained from solving a system of equations (Yamamoto and Landin, 2013), as shown in Equation (4).

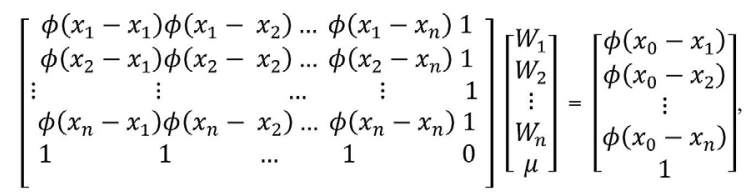

on what,

$\mu$ - is the additional parameter to include the nonbias condition in the multiquadric equation system.

According to Yamamoto and Landim (2013), categorical variables can be measured on a nominal or ordinal scale, and, whatever the scale, there is a discrete number of types. Let $k$ be the number of types of a categorical variable, $x_{0}$ is a nonsampled location and $\mathrm{n}$ represents values obtained at adjacent points. A weighted linear estimate of this location can be written as per Equation (5).

$Z^{*}{ }_{K S}\left(x_{0}\right)=m+\sum_{i=1}^{n} \lambda_{i}\left[Z\left(x_{i}\right)-m\right]$,

on what,

$m_{i}: E\left[Z\left(x_{i}\right)\right]$ - represents the means, which are assumed to be known, $m_{o}$ is the mean at the point $x_{0}$, and $\left\{\lambda_{i}, \mathrm{i}=1, n\right\}$ represents the weights associated with the $n$ data.

The non-sampled location and sampled points are part of a random function, considering the regionalized variables. The mean and variance of all locations are constant under the condition of second-order stationarity, depending only on Euclidean distances (Yamamoto and Landin, 2013).

According to Yamamoto and Landin (2013), the indicator functions obtained according to the binary coding can be manipulated numerically to interpolate a type at a non-sampled point, according to Equation (6) and Equation (7) 
$i^{*}{ }_{M Q}\left(x_{0} ; k\right)=\sum_{i=1}^{n} w_{j} i\left(x_{j} ; k\right)$,

on what the type of the categorical variable interpolated is given by the most likely value of

$i^{*}{ }_{M Q}\left(x_{0} ; k\right)$, where

$i^{*}{ }_{M Q}\left(x_{0} ; k_{\max }\right)=\max \left(i^{*}{ }_{M Q}\left(x_{0} ; k\right), k=1, \ldots, K\right)$,

on what,

$K$ : is the number of levels to be studied.

Spatial weights of the multiquadric equations needed to be corrected due to the presence of negative weights in the kriging and an algorithm was used for their elimination, as proposed by Rao and Joumel (1997). This algorithm was used for such correction. The five closest neighbors were considered, according to the method used (Yamamoto and Landin, 2013).

The software Surfer 12.0 (Golden Software 2014) was used to perform the interpolations of the grain production data in the 2016/2017 growing season using the NN method, while the software R (R Development Core Team, 2020) and Qgis 3.10.1 (Qgis.org. Qgis 3.10 2020) were used for the interpolation of data on the static capacity of warehouses through the multiquadric equations.

The input data for processing were constructed by files in the vector (points) format with the georeferenced location of the grain production points in the 2016/2017 growing season and the static capacity of warehouses in the 2017/2018 growing season (latitude and longitude in UTM). The entire database of the static capacity of warehouses was organized due to the repeated coordinates at various points and the presence of cases of different municipalities with equal coordinates.

The search radius of close values was considered for the analysis of the static capacity of warehouses using multiquadric equations. It was programmed to be variable with a maximum limit of 5 points, according to the methodology of Yamamoto and Landin (2013).
The discretization of data on the static capacity of warehouses required balance. The method used was Jenks natural breaks algorithm method, what identifies the break between classes according to Jenks (1977), being the classification that best represented the spatial distribution of data. The categories of the static capacity of warehouses were named as low (0,91 to 19,575 tons $)$, medium $(19,575$ to 72,649 tons $)$, and high $(72,649$ to 265,800 tons) to perform spatial interpolation using multiquadric equations.

The choice of this interpolator was associated with the nature the data, and the discrete variable (count) was transformed into categorical (low, medium and high) and also by the type of map that was desired to be obtained (Yamamoto and Landin, 2013).

\section{Results and discussion}

The descriptive statistics in Table 1 shows that the quantitative data of grain production in the 2016/2017 growing season had heteroscedasticities relative to their means, what indicates variability in the grain production, justifying the presence of skewness in the data (Table 1). The same behavior is observed in the static capacity of warehouses, what indicates deficiency the static capacity of warehouses in the municipalities of the state of Paraná, as shown in Table 1.

Figure $2 \mathrm{a}$ and Figure $2 \mathrm{~b}$ show the presence of skewness in the grain production data $(\mathrm{t})$. The data frequency in the histogram (Figure 2a) is located in higher magnitude in the first class. The boxplot (Figure 2b) showed that the data set showed skewness, evidenced by the presence of several discrepant points.

Figure 3 shows the estimated values of grain production in the 2016/2017 growing season using the NN spatial interpolation method. The map (Figure 3) shows regions with higher grain production than other regions.

The data on grain production showed high

\begin{tabular}{lccccccccc}
\hline Variables & Years & $\mathrm{n}$ & Min & $\bar{x}$ & Md & Max & Sd & CV $(\%)$ & Total \\
\hline Grain Production & $2016 / 2017$ & 399 & 0.015 & 98.620 & 64.42 & 772 & 114 & 115 & 39055 \\
Static Storage Capacity & $2017 / 2018$ & 2751 & 0.091 & 10.303 & 4.146 & 2658 & 167 & 162 & 28332 \\
\hline
\end{tabular}

Note: $n$ : number of warehouses for study the static storage capacity and number municipalities for grain production; min: minimum; $\bar{x}$ : mean; Md: median; Max: maximum; Sd: standard deviation; CV: coefficient of variation.

Source: own calculations.

Table 1: Descriptive statistics of grain production and static capacity of warehouses, in thousands of tons. 

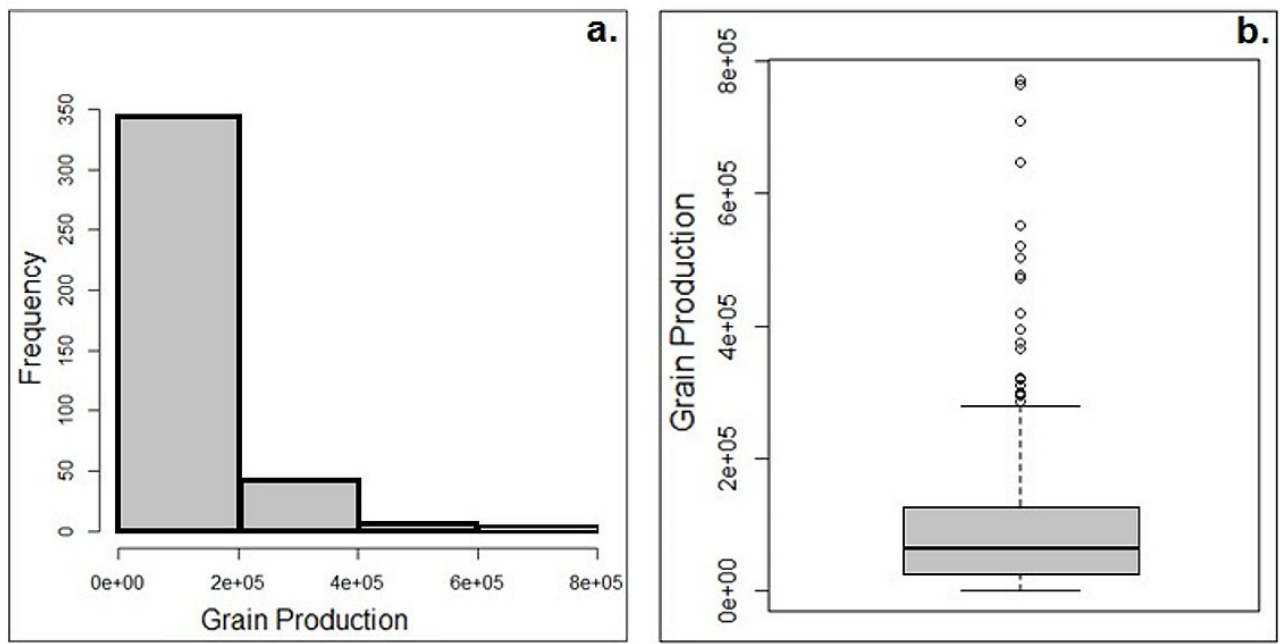

Source: own research

Figure 2: Grain production data. a Histogram. b Boxplot.

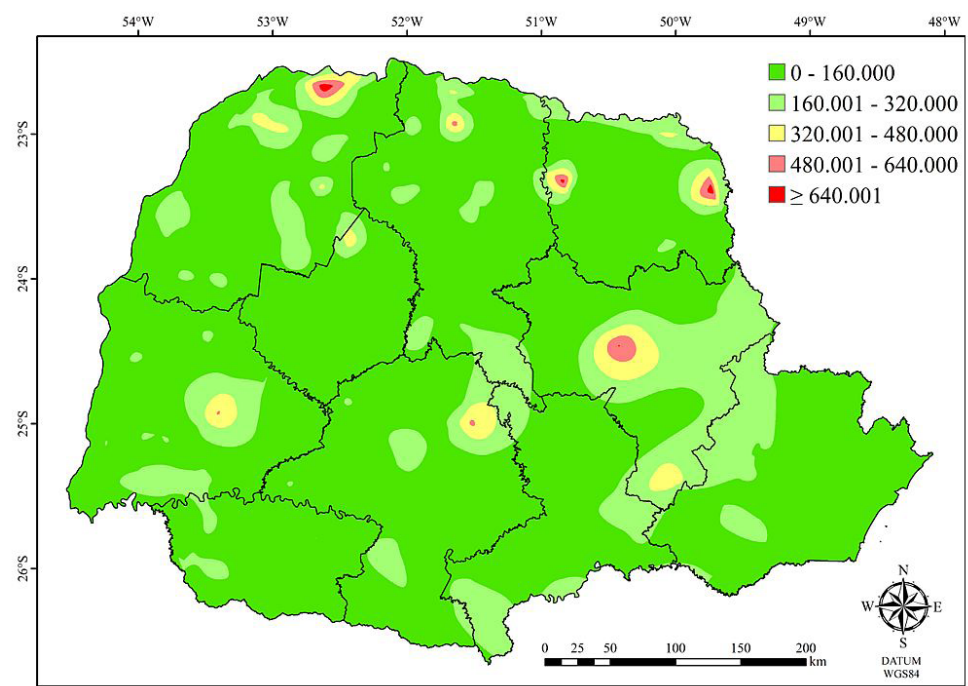

Source: own research

Figure 3: Estimated natural neighbor map related to the grain production (tons) in the 2016/2017 growing season by mesoregion of the state of Paraná, Brazil.

variability, considering the different analyzed locations. The meso-regions East-Central, SouthCentral, West, Northwest, and North presented the largest ranges of values. The ranges varied from 160,000 to 320,000 (light green hue), 320,000 to 480,000 tons (yellow hue) and 480,000 to 640,000 tons (rose and red hue). These results can be justified and represent the practical results obtained in these regions although they are estimated values (Figure 3).

The Northwest meso-region in the state of Paraná, that is, the region of the municipalities of Paranavaí, Querência do Norte, and Terra Rica, showed the highest values of grain production (Figure 3). This agricultural scenario became more evident from 2017 with the opening of an agro-industrial cooperative in this region (Seab, 2020). The mesoregions West and South-Central showed high grain production, which is justified by the large poultry and pig complexes and the presence of agro-industries processing and transforming grains into animal protein.

The meso-regions West, West-Central, and SouthCentral presented an interesting profile, with an intersection axis showing a high grain storage capacity.

Moreover, the presence of grain production ranging from 0 to 160,000 tons (dark green hue), that is, low grain production, in the ten mesoregions that 
make up the state of Paraná shows the spatial variability in the grain production. The WestCentral mesoregion presented an interesting profile of analysis, as grain production was low in practically all its extension (Figure 3, dark green hue). This region has a low rural population due to the workforce, corroborating with Alves, Andreica and Alcantara (2020), who reported that family farming predominates in the microregions of Campo Mourão and Goioerê, with small municipalities and small-scale production characterized by subsistence agriculture. Large industrial hubs are also observed in this meso-region, such as the textile industry. In this sense, Campo Mourão is the municipality that most contributes to soybean and corn the other municipalities have characteristics of small rural properties (Alves et al., 2020).

A similar profile is observed in the meso-regions Southwest, Southeast, and Metropolitan region (Figure 3, dark green hue). According to Seab (2020), the Southwest region is considered a major milk producer and has an expressive presence of textile industries, the Metropolitan region also presented low grain production (Figure 3, dark green hue), as this region has mostly urban characteristics with large clusters of different converting industries, such as the automotive hub (Alves et al., 2020).

The NN interpolation method presented an efficiency, corroborating with Liu and Chen (2018), who studied the NN interpolation method and identified the viability of this technique, stating that it is a solution procedure reliable and efficient.
Karyab, Hajimirmohammad-Ali and Bahojb (2019) reported that the $\mathrm{NN}$ interpolation method is appropriate, as it had a lower error rate in the mapping process in spatial data analysis.

Thus, the thematic map of the spatial distribution of grain production in the 2016/2017 growing season (Figure 3 ) showed that the highest production rates occurred in the meso-regions West, North-Central, East-Central, and South-Central. Additionally, the interpolation through the NN interpolator had a good performance in the spatialization of grain production, considering the 2016/2017 growing season.

The spatial interpolation method using multiquadric equations allowed constructing the estimated thematic map for the static capacity of warehouses for the 2017/2018 growing season, aiming at understanding the behavior and spatial variability of static storage capacities of warehouses (Figure 4).

The categories medium and high of the static capacity of warehouses were more present in the meso-regions North-Central, West-Central, West, and South-Central (Figure 4, yellow and rose hue). This result makes sense since the largest agroindustrial cooperatives and trading companies are located in these regions.

The large cooperatives that leverage the national agribusiness economy are in the West meso-region of the state of Paraná, such as the cooperatives that trade soybean and corn to other countries, as observed by Cima et al. (2020) and Costa et al. (2019).

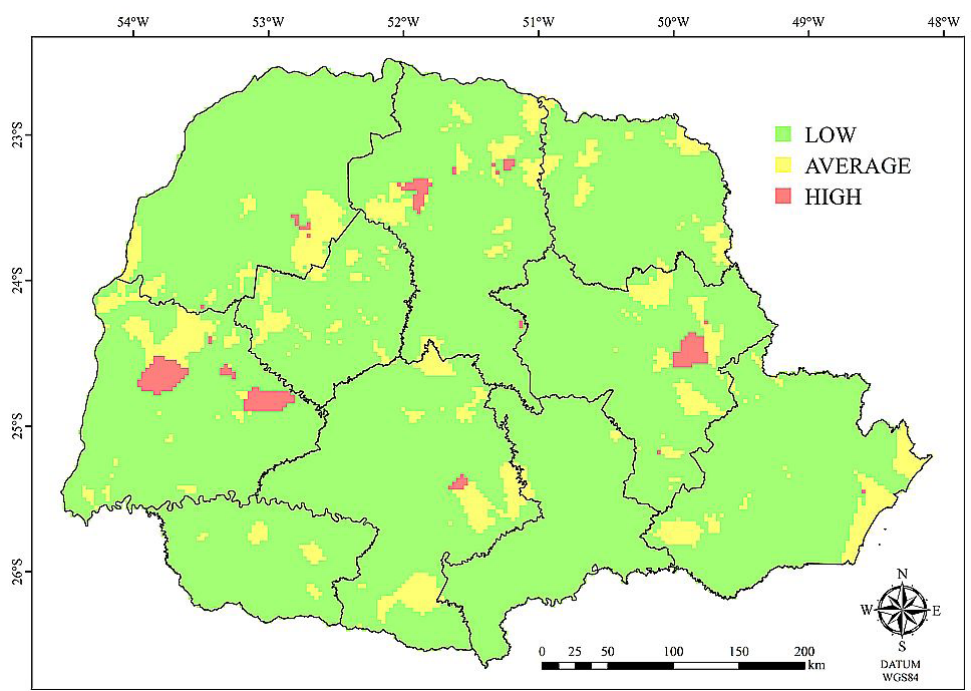

Source: own research

Figure 4: Map estimated using multiquadric equations related to the static capacity of warehouses in the $2017 / 2018$ growing season by meso-region in the state of Paraná, Brazil. 
An average and high storage capacity was observed in the Metropolitan meso-region, as it is a port area responsible for transporting the agricultural production of the state of Paraná through rivers. There was a presence of high static capacity of warehouses were observed in the meso-regions West, (Cascavel), South-Central (Guarapuava and Nova Laranjeira) and East-Central (Ponta Grossa), which is justified by the presence of agroindustrial cooperatives (Conab, 2019). Warehousing units were found only with the category of low static storage capacity in the Southeast meso-region (Figure 4, green hue), characterizing insufficient storage capacity relative to grain production in this region.

The results indicate that the static capacity of warehouses in the low classification was the most abundant category in the state of Paraná, followed by the medium category. The high category was observed less frequently (Figure 4).

The spatialized visualization of the thematic map shows that the high category was more present in the meso-regions Metropolitan, EastCentral, North-Central, Northwest, South-Central, and West (Figure 4, rose hue). In this case, the presence of grain storage units with a high static capacity, as observed by Cima et al. (2020).

The estimated map showed sharpness and clarity (Figure 4), allowing a better analysis of the precision in the results found, as observed by Costa et al., (2019). The classification high static capacity of warehouses is observed at low frequency in the state (Figure 4, green hue).

The medium classification, was present more frequently in the meso-regions North-Central, South-Central, West-Central, and West, with storage units with medium total static warehouse capacity.

The demand for warehouses in these regions does not meet the grain supply in its entirety. Similarly, Shah (2015) analyzed the shortcomings in grain storage in India and verificade that the rural sector does not have a structure for grain storage in the country. The most striking scenario is the high frequency of the low classification (Figure 4) for the static capacity of warehouses. This behavior occurs in all ten meso-regions in the state of Paraná. It shows the importance of the interpolation method through multiquadric equations applied in the agricultural data. In this sense, Alatorre et al., (2019) reported the importance of using interpolation using multiquadric equations to analyze the inefficiency of agricultural irrigation in furrows in the Laguna de Bustillos basin, Chihuahua, Mexico, and concluded that the method was efficient.

Figure 4 shows that the interpolation of the spatial location of the static capacities of warehouses varied most frequently from low to medium classification. It shows that the static capacities of warehouses in the state of Paraná are small to medium-sized, thus not following the fast pace of grain production (Seab, 2020).

These results show the importance of the spatial interpolation method through multiquadric equations (Patel and Rastogi, 2017; Amantéa et al., 2018). The temporal and spatial behaviors of the total static capacities of warehouses evidence a predominance of the total static capacity of small warehouses in the state of Paraná, corroborating with the statistics that show the great gap of the accelerated advance of the total grain production relative to the static storage capacities. The deficit of warehouses in the state of Paraná is worrying when compared to the in grain production that has been observed in recent years. Cima et al., (2020) found similar results.

\section{Conclusion}

The result showed that the interpolation using the NN method was efficient in analyzing the grain production (tons) in the state of Paraná. The use of the $\mathrm{NN}$ interpolator is convenient. It showed that grain production on a larger scale is centered in the meso-regions East-Central, North, Northwest, and part of South-Central and West. Expressive spatial variability was observed in grain production. A similar spatial behavior regarding the static capacity of warehouses was observed in the 399 municipalities of the state of Paraná by means of the interpolation using multiquadric equations. A low static capacity of warehouses was observed in practically the entire state of Paraná, which justifies the insufficiency of storage units relative to the grain production, mainly in the mesoregions West, Southwest, and Northwest, which show a high grain production but a low storage capacity of warehouses. The spatial interpolation of the static capacity of warehouses showed that small storage units for agricultural storage occur more frequently in the state of Paraná. The low, medium and high categories showed spatial variability regarding the static capacity of warehouses, and the high category showed the highest variation. 


\section{Acknowledgments}

The authors would like to thank the Coordination for the Improvement of Higher Education Personnel - Brazil (CAPES) - Financing Code 001 for financial support, the National Council for Scientific and Technological Development $(\mathrm{CNPq})$, the Graduate Program in Regional Development and Agribusiness (PGDRA) at the Western Paraná State University (UNIOESTE), and the of Spatial Statistics Laboratory (LEE-LISA).

Corresponding authors

Elizabeth Giron Cima

Western Paraná State University (UNIOESTE),

R. Universitária, 1619 - Universitário, Cascavel-PR, Brazil

E-mail:egcima74@gmail.com

\section{References}

[1] Alatorre, L. C., Granados., A, Bravo, L. C., Torres, M. E., Wiebe, L. C., Uc, M. I., González, M. O., Sanchez, E. and Rojas, H. L. (2019) "Agricultural furrow irrigation inefficiency in the basin of Bustillos Lagoon, Chihuahua, Mexico: geometric characteristics of agricultural plots and aquifer depletion", Tecnología y Ciencias del Agua, Vol. 10, No. 5, pp. 241-281. ISSN 2007-2422. DOI 10.24850/j-tyca-2019-05-10.

[2] Alves, L. R., Andreica., A. B. and de Alcântara, I. R. (2020) "Using Industry 4.0 Tools for Increasing Competitiveness of Clusters in Western Paraná", Brazilian Journal of Development, Vol. 6, No. 8, pp. 56648-56672. ISSN 2525-8761. DOI 10.34117/bjdv6n8-179.

[3] Aanjos, R. S., Candeias., A. L. B. and Nóbrega, R. S. (2017) "Mapeamento da precipitação estimada e observada no semiárido pernambucano e sua relação com a modelagem de dados espaciais", Revista Brasileira de Cartografia, Vol. 69, No. 3, pp. 447-462. ISSN 1808-0936.

[4] Amantéa, R. P., Fortes, M., Ferreira, W. R. and Santos, G. T. (2017) "Energy and exergy efficiencies as design criteria for grain dryers", Drying Technology, Vol. 36, No. 4, pp. 491-507. E-ISSN 1532-2300, ISSN 0737-3937. DOI 10.1080/07373937.2017.1409232.

[5] Bachir, H., Semar., A. and Mazar, A. (2016) "Statistical and geostatistical analysis related to geographical parameters for spatial and temporal representation of rainfall in semiarid environments: the case of Algeria", Arabian Journal of Geoscience, Vol. 9, pp. 1-12. E-ISSN 1866-7538, ISSN 1866-7511. DOI 10.1007/s12517-016-2505-8.

[6] Baroni, G., Benedeti, P. and Seidel, D. (2017) "Cenários prospectivos da produção e armazenagem de grãos no Brasil", Revista Thema, Vol. 14, No. 4, pp. 55-64. ISSN 2177-2894. E-ISSN 2177-2894. DOI 10.15536/thema.14.2017.55-64.452. (in Portuguese).

[7] Belinha, J., Azevedo, J. M. C., Dinis, L. M. J. S. and Jorge, R. M. N. (2017) "The Natural Neighbor Radial Point Interpolation Method in Computational Fracture Mechanics: a 2D Preliminary Study", International Journal of Computational Methods, Vol. 14, No. 4, pp. 25. ISSN 1550-2295. DOI 10.1142/s0219876217500451.

[8] Briani, M., Caramellino, L. and Zanette., A. (2017) "A hybrid tree/finite-difference approach for Heston-Hull-White-type models", Journal of Computational Finance, Vol. 21, No. 3, pp. 1-45. ISSN 1755-2850. DOI 10.21314/jcf.2017.333.

[9] Chen, J. and Cai, Z. (2019) "Cardinal MK-spline signal processing: spatial interpolation and frequency domain filtering", Information Sciences, Vol. 495, pp. 116-135. ISSN 0020-0255. DOI 10.1016/j.ins.2019.04.056.

[10] Cicolin, M. O. L. and Oliveira, R. L. A. (2016) "Avaliação de desempenho do processo logístico de exportação do milho brasileiro. Uma aplicação da Análise Envoltória dos Dados - DEA", The Journal of Transporte Literature. Vol. 10, No. 3, pp. 30-34. ISSN 2238-1031. DOI 10.1590/2238-1031.jtl.v10n3a6. 
[11] Cima, E. G., Uribe-Opazo, M. A., Guedes, L. P. C., Rocha-Junior, W. F. and Johann, J. A. (2020) "Grain Storage System in the State of Paraná, Brazil, from the Perspective of Multivariate Analysis", Engenharia Agrícola, Vol. 40, No. 3, pp. 280-288. ISSN 1809-4430. DOI 10.1590/1809-4430-Eng.Agric.v40n3p280-288/2020.

[12] Cima, E. G., Uribe-Opazo, M. A., Johann, J. A., Rocha-Junior, W. F. and Becker, W. R. (2020) "Analysis of static and dynamic capacity in Paraná State, Brazil", Acta Scientiarum Agronomy, Vol. 42, pp. 1-13. E-ISSN 1807-8621. DOI 10. 4025/actasciagron.v42i1.44440.

[13] CONAB, Companhia nacional de abastecimento (2019) "Safra Brasileira de Grãos". [Online]. Available: https://www.conab.gov.br/info-agro/safras/graos. [Accessed: 26 June 2020].

[14] Costa, H. S., Seidel, E. J., Pazini, J. B., Silva, A. M., Silva, F. F., Martins, J. F. S. and Barrigossi, J. A. F. (2019) "Mapping of spatiotemporal distribution of Tibraca limbativentris Stal (Hem.: pentatomidae) in flooded rice crop in southern Brazil", Revista Brasileira de Entomologia, Vol. 63, No. 3, pp. 205-211. ISSN 1806-9665. DOI 10.1016/j.rbe.2019.04.001.

[15] Dalposso, G. H., Uribe-Opazo, M. A., Johann, J. A., Bastiani, F. and Galea, M. (2019) "Geostatistical Modeling of Soybean Yield And Soil Chemical Attributes Using Spatial Bootstrap", Engenharia Agrícola, Vol. 39, No. 3, pp. 350-357. ISSN 1809-4430. DOI 10.1590/1809-4430-eng.agric.v39n3p350-357/2019.

[16] Fliehr, O., Zimmer, Y. and Smith L. (2019) "Impacts of Transportation and Logistics on Brazilian Soybean Prices and Exports", Transportation Journal, Vol. 58, No. 1, pp. 65. ISSN 5000-0782. DOI 10.5325/transportationj.58.1.0065.

[17] Gao, W., Zhang., X. and Zhou, X. (2020) "Multiquadric quasi-interpolation for integral functionals", Mathematics and Computers in Simulation, Vol. 177, pp. 316-328. ISSN 0378-4754. DOI 10.1016/j.matcom.2020.04.015.

[18] Golbabai, A. and Mohebianfar, E. (2017) "A new method for evaluating options based on multiquadric RBF-FD method", Applied Mathematics and Computation, Vol. 308, pp. 130-141. ISSN 0096-3003. DOI 10.1016/j.amc.2017.03.019.

[19] Jenks, G. (1977) "Optimal data classification for choropleth maps. Departament of Geography", University Kansas, pp. 24. ISSN 02516365.

[20] Karyab, H., Hajimirmohammad-ali, R. and Bahojb, A. (2019) "A lumped-parameter model for investigation of nitrate concentration in drinking water in arid and semi-arid climates and health risk assessment", Journal of Environmental Health Science and Engineering, Vol. 17, No. 1, pp. 457-465. DOI 10.1007/s40201-019-00364-Z.

[21] Ku, C. Y., Liu, C. Y., Xiao, J. E. and Hsu, S. M. (2020) "Multiquadrics without the Shape Parameter for Solving Partial Differential Equations", Symmetry, Vol. 12, No. 2, pp. 1-20. ISSN 2073-8994. DOI $10.3390 /$ sym 12111813 .

[22] Li, Q. H., Chen S. S. and Luo, X. M. (2016) "Using Meshless Local Natural Neighbor Interpolation Method to Solve Two-Dimensional Nonlinear Problems", International Journal of Applied Mechanics, Vol. 8, No. 5, pp. 1-20. ISSN 1758-826X DOI 10.1142/s1758825116500691.

[23] Liu, Y. S. and Chen, S. S. (2018) "Modeling of magneto-electro-elastic problems by a meshless local natural neighbor interpolation method", Engineering Analysis with Boundary Elements 93, Vol. 93, pp. 143-149. ISSN 0955-7997. DOI 10.1016/j.enganabound.2018.05.002.

[24] Martyshko, P. S., Ladovskiy, I. V. and Byzov, D. D. (2016) "Stable methods of interpretation of gravimetric data", Doklady Earth Sciences, Vol. 471, No. 2, pp. 1319-1322. ISSN 1531-8354. DOI $10.1134 / \mathrm{s} 1028334 \times 16120199$.

[25] Millan, V. I. E., Garcia, R. C. and Sanchez-Azofeifa, G. A. (2020) "Crop Loss Evaluation Using Digital Surface Models from Unmanned Aerial Vehicles Data", Remote Sensing, Vol. 12, No. 6, pp. 1-25. ISSN 2072-4292. DOI 10.3390/rs12060981. 
[26] Moradi, E., Rodrigo-Comino, J., Terol, E., Mora-Navarro, G., Silva, A. M., Daliakopoulos, I. N., Khosravi, H., Fernández, M. P. and Cerdà, A. (2020) "Quantifying Soil Compaction in Persimmon Orchards Using ISUM (Improved Stock Unearthing Method) and Core Sampling Methods", Agriculture, Vol. 10, No. 7, pp. 266. ISSN 2077-0472. DOI 10.3390/agriculture10070266.

[27] Musashi, J. P., Pramoedyo, H. and Fitriani, R. (2018) "Comparison of Inverse Distance Weighted and Natural Neighbor Interpolation Method at Air Temperature Data in Malang Region", Cauchy, Vol. 5, No. 2, pp. 48-54. E-ISSN 2477-3344. DOI 10.18860/ca.v5i2.4722.

[28] Narany, T. S., Ramli, M. F., Aris, A. Z., Sulaiman, W. N. A. and Fakharian, K. (2014) "Groundwater irrigation quality mapping using geostatistical techniques in Amol-Babol Plain, Iran", Arabian Journal of Geoscience, Vol. 8, No. 2, pp. 961-976. DOI 10.1007/s12517-014-1271-8.

[29] Nourani, V., Mousavi, S. and Sadikoglu, F. (2017) "Conjunction of Artificial IntelligenceMeshless Methods for Contaminant Transport Modeling in Porous Media: An Experimental Case Study", Journal of Hydroinformatics, Vol. 20, No. 5, pp. 1163-1179. ISSN 1464-7141. DOI 10.2166/hydro.2017.172.

[30] Paludo, A., Becker, W. R., Richetti, J. and Silva, L. C. A., Johann, J. A. (2020) "Mapping Summer Soybean and Corn With Remote Sensing on Google Earth Engine Cloud Computing in Parana State - Brazil", International Journal of Digital Earth, Vol. 13, No. 12, pp.1624-1636. ISSN 1753-8947. DOI 10.1080/17538947.2020.1772893.

[31] Patel, S. and Rastogi, A. K. (2017) "Meshfree Multiquadric Solution for Real Field Large Heterogeneous Aquifer System", Water Resources Management, Vol. 31, No. 9, pp. 2869-2884. ISSN 1573-1650. DOI 10.1007/s11269-017-1668-8.

[32] Qgis.Org. Qgis 3.10 (2020) "Geographic Information System Installation Guide. QGIS Association", Electronic document. [Online]. Avaiable: https://github.com/qgis/QGIS/blob/master/INSTALL.md. [Accessed: 15 Dec. 2020].

[33] R Development Core Team, R (2020) "A language and environment for statistical computing", Vienna, Austria: R Foundation for Statistical Computing, ISBN 3-90005107-0. [Online]. Avaiable: http://www.R-project.org [Accessed: Jun. 2020].

[34] Rao, S. E. and Journel, A. G. (1997) "Deriving conditional distributions from ordinary kriging", In: Baafi, E.Y, Schofield, N. A, Geostatistics Wollongong '96, Boston, Kluwer Academic Publishers, pp. 92-102. ISBN 978-0-89181-704-8.

[35] Saeedpanah, I., Golmohamadi, A. R. and Sarkardeh, H. (2020) "An Efficient Radial Basis Function Meshfree Local Petrov-Galerkin Method for Modeling the Unidirectional Fully Developed Fluid Flow", Journal of Applied Fluid Mechanics, Vol. 13, No. 2, pp. 491-497. ISSN 1735-3572. DOI 10.29252/jafm.13.02.30301.

[36] Shah, M. A. (2015) "Accelerating Public Private Partnership in Agricultural Storage Infrastructure in India", Global Journal of Management and Business, Vol. 15, No. 13, pp.1-10. ISSN 2249-4588. DOI 10.5958/0976-478X.2016.00001.X.

[37] Sampedro, G. A. R., Soriano, M. N., Yumang, A. N. and Dimaunahan, E. D. (2019) "Rapid Microscopic Analysis Using Natural Neighbor Interpolation", Proceedings of the $9^{\text {th }}$ International Conference On Biomedical Engineering And Technology - ICBET' 19, pp. 166-169. DOI 10.1145/3326172.3326218.

[38] Santos, T. C. and Yamamoto, J. K. (2019) "Ore Resource Estimation Based on Radial Based Functions - Case study on União Luiz and Morro do Carrapato Gold Deposits (Alta Floresta Gold Province)", REM - International Engineering Journal, Vol. 72, No. 3, pp. 493-499. ISSN 2448-167X. DOI 10.1590/0370-44672018720154.

[39] SEAB Secretaria da Agricultura e do Abastecimento do Paraná (2020) "Banco de Dados da Produção Agropecuária no Paraná. Situação mensal de plantio, colheita e comercialização de produtos agrícolas no Paraná". [Online]. Avaiable: http://www.agricultura.pr.gov.br/. [Accessed: 12 July 2020]. 
[40] Sekulić, A., Kilibarda, M., Heuvelink, G. B. M., Nikolić, M. and Bajat, B. (2020) "Random Forest Spatial Interpolation", Remote Sensing, Vol. 12, No. 10, pp. 1-29. ISSN 2072-4292. DOI 10.3390/rs12101687.

[41] Seydaoğlu, M. (2019) "A Meshless Method for Burgers’ Equation Using Multiquadric Radial Basis Functions With a Lie-Group Integrator", Mathematics, Vol. 7, No. 2, pp.1-11. ISSN 2227-7390. DOI 10.3390/math7020113

[42] Sibson, R. (1981) "A brief description of natural neighbour interpolation", John Wiley \& Sons, pp.21-36. ISBN 0471280399.

[43] Soleymani, F. and Ullah., M. Z. (2018) "A multiquadric RBF-FD scheme for simulating the financial HHW equation utilizing exponential integrator", Calcolo, Vol. 55, No. 4, pp. 1-26. ISSN 1126-5434. DOI 10.1007/s10092-018-0294-z.

[44] Song, D. P., Li, H., Liu, S. J., Zou, G.Y . and Liu, D. S. (2019) "A geostatistic investigation of the comprehensive evaluation of fertility and spatial heterogeneity of forest soil nutrients in hilly and mountainous regions of southern China", Arabian Journal of Geosciences, Vol. 12, No. 9 , pp. 1-9. E-ISSN 1866-7538, ISSN 1866-7511. DOI 10.1007/s12517-019-4480-3.

[45] Steiner Neto, P. J., Datta, D., Steiner, M. T. A., Canciglieri-Júnior, O., Figueira, J. R., Detro, S. P. and Scarpin, C. T. (2017) "A Multi-Objective Genetic Algorithm Based Approach for Location of Grain Silos in Paraná State Of Brazil", Computers \& Industrial Engineering, Vol. 111, pp. 381-390. ISSN 0360-8352. DOI 10.1016/j.cie.2017.07.019.

[46] Surfer Version 12.0. (2020) "Golden Software Surfer", Colorado: Golden Software, LLC. [Online]. Avaiable: http://www.goldensoftware.com. [Accessed: 19 November. 2020].

[47] Tesidaev, A. (2016) "Parallel Algorithm for Natural Neighbor Interpolation", Journal Ceur Workshop Proceedings, pp. 78-83.

[48] Uribe-Opazo, M. A., Borssoi, J. A. and Galea, M. (2012) "Influence diagnostics in Gaussian spatial linear models", Journal of Applied Statistics, Vol. 39, No. 3, pp. 615-630. E-ISSN 1360-0532, ISSN 0266-4763. DOI 10.1080/02664763.2011.607802.

[49] Voronoi, G. (1908) "Nouvelles applications des paramètres continus à la théorie des formes quadratiques. Deuxième mémoire. Recherches sur les parallélloèdres primitifs", Journal für die Reine und Angewandte Mathematik (Crelles Journal), Vol. 134, pp.198-287. ISSN 0075-4102. ISSN 1435-5345. DOI 10.1515/crll.1908.134.198.

[50] Yamamoto, J. K. and Landim, P. M. B. (2013) "Geoestatística: conceitos e aplicações": Oficina de Textos. ISBN 978-85-7975-077-9.

[51] Yamamoto, J. K., Kikuda, A. T., Rampazzo, G. J. and Leite, C. B. B. (2018) "Uncertainties Associated with Arithmetic Map Operations in GIS", Anais da Academia Brasileira de Ciências, Vol. 90, No. 21, pp. 2025-2048. ISSN 1678-2690. DOI 10.1590/0001-3765201820170589.

[52] Zdráhal, I., Hrabálek, M., Kadlec, P. and Krpec, O. (2021) "Brazil's Comparative Advantages and Specialization Dynamics in Agri-food Trade", Agris on-line Papers in Economics and Informatics, Vol. 13, No. 2, pp. 121-139. ISSN 1804-1930. DOI 10.7160/aol. 2021.130210.

[53] Zhang, H., Chen, Y., Guo, C. and Fu, Z. (2014) "Application of Radial Basis Function Method for Solving Nonlinear Integral Equations", Journal of Applied Mathematics, Vol. 2014, 8 p. ISSN 1687-0042. DOI 10.1155/2014/381908. 